\title{
VEINTICINCO AÑOS DE LA INSTITUCIÓN DE LA REFORMA CONSTITUCIONAL
}

M. ${ }^{a}$ VICTORIA GARCIAA-ATANCEY GARCÍA DE MORA

Profesora Titular de Derecho Constitucional UNED 


\title{
SUMARIO
}

\begin{abstract}
INTROdUCCIÓN. I. BREVES CONSIDERACIONES DE LA REFORMA CONSTITUCIONAL COMO INSTRUMENTO POLÍTICO EN LA HISTORIA DEL CONSTITUCIONALISMO. II. SIGNIFICADO DE LA REFORMA CONSTITUCIONAL: PERFIL AMBIVALENTE DEL INSTITUTO DE REFORMA CONSTITUCIONAL. III. JUSTIFICACIÓN DE LA ACTIVIDAD REFORMADORA COMO CONSECUENCIA DE LA DIALÉCTICA: PERMANENCIA-CAMBIO. IV. BALANCE DE LA ACTIVIDAD DE REFoRMA dE LA Constitución EsPañola de 1978. IV.A. Derecho comparado y Maastricht. IV.B. Balance de la Reforma Constitucional en España. IV.B.1. Concepción de la Reforma Constitucional por el Constituyente. IV.B.2. Supuestos de actividad reformadora en la Constitución Española de 1978. V. Perspectivas de Posibles READAPTACIONES DEL TEXTO CONSTITUCIONAL TRAS 25 AÑOS DE EXISTENCIA: LA REFORMA CONSTITUCIONAL ANTE LAS DEMANDAS SOCIALES DE NUEVA GENERACIÓN.
\end{abstract}




\title{
VEINTICINCO AÑOS DE LA INSTITUCIÓN DE LA REFORMA CONSTITUCIONAL
}

\author{
POR \\ M. ${ }^{a}$ VICTORIA GARCÍA-ATANCEY GARCÍA DE MORA \\ Profesora Titular de Derecho Constitucional \\ UNED
}

\section{INTRODUCCIÓN}

El estudio de la reforma constitucional es de todo punto imprescindible para lograr una visión completa de cualquier texto constitucional en particular, $y$ del Derecho constitucional en general, de forma que - como señala Mirkine-Guetzevitch ${ }^{1}$ - no puede considerarse completa la observación de la teoria constitucional, si se contempla ésta desde una perspectiva estrictamente estática de la revisión constitucional.

Por eso, la previsión de revisión es una cláusula que desde los origenes del constitucionalismo no ha dejado de configurar una parte básica de los textos fundamentales.

La revisión o reforma constitucional puede ser analizada desde distintas dimensiones según se aborde su estudio desde una pers-

1 Mirkine-GuetZEVITCH, B.: Les nouvelles tendences du droit constitutionnel,

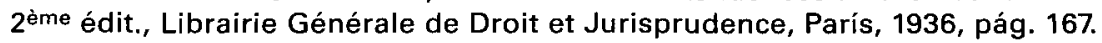


pectiva política o estrictamente jurídica, que será en la que nos detendremos cuando nos refiramos a su definición.

\section{BREVES CONSIDERACIONES DE LA REFORMA CONSTITUCIONAL COMO INSTRUMENTO POLIITICO EN LA HISTORIA DEL CONSTITUCIONALISMO}

Por la especial trascendencia que desde el enfoque político asume esta institución constitucional, no podemos sino referirnos, aunque de forma somera, a la misma desde su análisis político.

A lo largo de la historia de las formaciones políticas, se observa una sucesión de acontecimientos que se concatenan como señala Hint$z^{2}$ : así a la época del Estado feudal siguió la del estado estamental y a ésta, con o sin estadio intermedio del absolutismo, le sucedió la etapa del Constitucionalismo.

El origen del constitucionalismo se inserta en un contexto histórico, en que el interés general de la burguesía dominante intenta garantizar su status político y su dominio.

El constitucionalismo escrito nace, pues, como aduce De Esteban $^{3}$, como intento de asegurar los derechos de los ciudadanos, expresados a través de la clase burguesa ascendente, identificada con la nación, siendo la burguesía el estrato social más interesado en realizar el cambio social revolucionario que derribó al antiguo régimen, como señala Lucas Verdú4.

En este mismo sentido se manifiesta Wheare ${ }^{5}$ cuando se refiere a que las constituciones, una vez adoptadas, tienden a reflejar las creencias e intereses dominantes, o el compromiso entre creencias o intereses encontrados, lo que queda ampliamente demostrado en el ensayo publicado por A. Beard en 1913 bajo el título: An economic

2 HiNTZE, O.: "Las condiciones histórico universales de la Constitución representativa", en Historia de las formas políticas, Biblioteca de Política y Sociología, Revista de Occidente, Madrid, 1968, pág. 104.

3 De Esteban, J.: Constituciones españolas y extranjeras, vol. I, Taurus, Madrid, 1977, pág. 25.

4 LuCAS Verdú, P.: Curso de Derecho Político, vol. II, 2. ${ }^{a}$ ed., revisada, Tecnos, Madrid, 1977, pág. 613.

5 WheARE, K. C.: Las Constituciones modernas, Labor, Barcelona, 1971, págs. 73-74. 
interpretation of the Constitution of the United States, en que se mantiene la tesis de que la mencionada Constitución, lejos de haber sido creada por todo el pueblo, obedeció a la iniciativa de un grupo de la población, cuyos intereses habían sido perjudicados con el sistema de gobierno en vigor con la Confederación de 1777.

No resulta difícil, pues, comprender que ante tal circunstancia histórica concreta en que se fundamenta el constitucionalismo clásico, los propios textos fundamentales contribuyen a crear y defender el nuevo orden que respondería a la exigencia de la burguesía, como aduce De Cabo6.

Una vez que las circunstancias históricas van evolucionando, y que la burguesía ve consolidados sus objetivos primordiales que justificaron la defensa de aquel orden que expresa la particular ideologia burguesa: seguridad jurídica, propiedad privada, libertad personal y económica, cabe plantearse si el constitucionalismo actual ha de seguir adoptando una actitud defensiva y de permanencia o, si por el contrario, esa actitud debe rechazarse como obsoleta, frente a las nuevas circunstancias sociales que invocan una tendencia a la transformación, al cambio como factor democratizador de la dinámica social.

La pretensión de cierto sector de la doctrina representado por De Cabo, de hacer de la teoría y de la práctica constitucional burguesa una transformación en práctica constitucional democrática, nos parece un planteamiento muy estimable, para evitar que la Constitución se convierta en frase feliz Lassalliana "en hoja de papel», si bien discrepamos respecto al autor, en orden, a algunos de los elementos que aporta para tal fin, como es el de la simplificación del instituto de revisión y desaparición de límites a la reforma constitucional, así como su máxima flexibilización procedimental, porque consideramos que la ausencia de éstos, pondría en peligro no sólo la identificabilidad del texto constitucional sobre el que se pretende activar la transformación, sino porque además, la función de defensa, pareja al instituto de reforma, quedaría vacía de contenido y no parece que la solución para proveer al cambio, cara a nuevas exigencias sociales que requieren un constitucionalismo de transformación proclive a nuevos postulados democráticos, fuera la de tender hacia tales objetivos si en definitiva estos hitos, una vez alcanzados carecen de un dispositivo suficientemente

6 De Cabo Martín, C.: "Sobre la función histórica del constitucionalismo y sus posibles transformaciones», Publicaciones del Departamento de Derecho Politico, Universidad de Salamanca, 1978, págs. 6-8. 
eficaz para protegernos, toda vez que los intereses de los diversos grupos políticos presionarian según sus conveniencias, para su remoción o su transformación en otros más afines a su propio interés.

En todo caso, valga señalar como aduce De Esteban ${ }^{7}$ que las democracias modernas han conseguido -a pesar del carácter de "defensa-permanencia" que asumió el sistema de reforma constitucional del constitucionalismo demoliberal - determinadas conquistas como son: el mayor intervencionismo estatal en la vida económica $y$ social, mayor aperturismo institucional a un más amplio espectro de ciudadanos, soslayando prejuicios de raza, sexo y edad; extensión del sufragio; adopción de derechos sociales y económicas, etc., lo cual pone de manifiesto, a nuestro juicio, que no es el dispositivo de revisión constitucional contemplado por el constitucionalismo demoliberal, caracterizado por su proyección defensiva y de permanencia del orden constitucional, lo que frena o dificulta la consecución de determinados objetivos o transformaciones sociales democráticas, puesto que algunos de éstos se han conseguido "a pesar de las connotaciones» retrógradas y defensivas «que han tenido las cláusulas de reforma en el constitucionalismo clásico»; sino que superadas en la actualidad las circunstancias históricas que posibilitaron el triunfo burgués y su estabilidad, los posteriores hitos alcanzados en torno a una transformación progresiva del constitucionalismo hacia una filosofía democrática, son susceptibles de ser frenados o tergiversados por la función más o menos soterrada, de la actividad partidista de las fuerzas políticas existentes en la sociedad, $y$ no por el hipotético freno de la actividad revisora.

Por esta razón nos parece rechazable la crítica de De Cabo cuando atribuye al carácter de defensa y permanencia del constitucionalismo clásico, que tiende hacia una rigidez constitucional, la causa de anclamiento constitucional, cobrando especial relevancia el dispositivo de reforma de las constituciones, como instrumento automáticamente capaz de aplicar las transformaciones de que todo texto fundamental está necesitado, no sólo impulsando la función transformadora de la Constitución hacia una sociedad democrática - ya que mediante la cláusula de revisión, posibilita el cambio - , sino también como medio que garantiza - de manera jurídica y aséptica (esto es, al margen de las pretensiones políticas) - la consecución y permanencia de tales eventos.

7 De Esteban, J.: Constituciones españolas y extranjeras, op. cit., pág. 41. 
Es precisamente en esta línea de preservación de la Ley Superior de las mil contingencias políticas que pueden interferir en el auténtico "telos» de la Constitución, en donde la institución de la reforma adquiere especial relieve considerada desde la perspectiva jurídica, como instrumento defensivo -siempre dentro de ciertos límites - de las diferentes posiciones políticas, que ven en la posibilidad de reformar la Ley Fundamental, un instrumento político proclive a sus fines, a tenor de sus propias conveniencias. No es difícil de hecho ver en determinadas campañas electorales las promesas más o menos veladas con que algunas formaciones políticas prometen, si alcanzar el poder, lograr una mayor adecuación del texto constitucional a su propia filosofía política; que frecuentemente se alinean en torno a una especifica sintonía política, llegando así a configurar una medio respecto al cual el electorado es especialmente sensible, y por tanto predispuesto a elegir la opción política con la cual más afinidad encuentre.

Por eso, en nuestra opinión, es precisamente viendo en el dispositivo jurídico de reforma un instrumento de garantía de la Constitución, y no por el contrario un lastre o rémora frente a las necesarias transformaciones que un texto fundamental precisa, como verdaderamente se consigue superar el carácter peyorativo que implica el uso de la reforma, con claros matices políticos electoralistas que producirían modificaciones fortuitas e imprevisibles, para, por el contrario, posibilitar cambios que la Ley Fundamental requiere para su acomodo a las nuevas exigencias sociales y políticas. En definitiva, para asumir aquel proceso de Derecho transitorio cara a un horizonte más avanzado, social y democrático.

\section{SIGNIFICADO DE LA REFORMA CONSTITUCIONAL: PERFIL AMBIVALENTE DEL INSTITUTO DE REFORMA CONSTITUCIONAL}

Una Constitución en sentido formal exige que su modificación sea más difícil que cualquier modificación que afectara a cualquier otra ley ordinaria. Lo que sólo es predicable de aquellas constituciones de carácter escrito, esto es, que asume la forma de un estatuto.

Hay Estados, como Gran Bretaña, que no tienen Constitución "escrita" y, por tanto, carecen de documento formal y solemne que se denominaría Constitución, por lo que adopta el carácter de derecho consuetudinario, y no se diferencia de las demás leyes ordinarias. 
Pero la mayoria de los casos, cuando tal diferencia existe, cuando existe una Constitución formal, las leyes constitucionales -como señala Kelsen ${ }^{8}-$ se distinguen de las ordinarias tanto por su promulgación, como en su reforma y abrogación que será más difícil que en el caso de las ordinarias, ya que si existe un procedimiento especialmente solemne para su creación, sus efectos han de proyectarse de igual modo en los supuestos de reforma, distinguiéndose asi de las demás leyes ordinarias.

Entendida pues la Constitución como el Código político de un país en que se traduce su forma de existencia política, parece lógico que pretenda un mínimo de estabilidad y seguridad, que se materializará en que sus modificaciones, normalmente, se realicen, no sin penosos esfuerzos, y que no impida, por otra parte, su adecuación a las nuevas exigencias sociales y políticas. Desde esta óptica hay que señalar que la función de reforma responde a la necesidad de adaptar el texto constitucional a las contingencias que presenta el devenir político social.

Así, se advierte una tendencia a la inmutabilidad de las leyes constitucionales, si bien no absoluta, pues, como sabemos, la soberanía nacional puede siempre cambiar su Constitución. La admisibilidad de este inmovilismo sería dar la espalda al progreso.

La función integradora que asume la Constitución que postulara Smend ${ }^{9}$, para soslayar la posible divergencia entre la Constitución normativa y la Constitución real que denunció Ferdinand Lassalle ${ }^{10}$ habría de desembocar necesariamente en un resultado que materializa el acoplamiento de dos dimensiones - jurídica y real- de diferente naturaleza pero no contradictorias.

Posibilitar esa armoniosa conjugación es el fin próximo a que aspiran los dispositivos de reforma que prevén las Constituciones rígidas. Sin embargo, no siempre es fácil conseguir un equilibrio, cuando se activan los institutos de revisión, en virtud del cual se permita

8 KeLSEN, H.: Historia General del Derecho y del Estado, Textos Universitarios; México, 1979, pág. 147.

9 Smend, R.: Constitución y Derecho Constitucional, Centro de Estudios Constitucionales, Madrid, 1985, pág. 201. «El Derecho Constitucional debe garantizar, en su calidad de sistema integrativo el cumplimiento de una tarea que está sujeta a cambio ... (...) Este cambio puede tener lugar fuera del propio Derecho Constitucional, siempre que se dé dentro del ámbito social de las fuerzas espontáneas».

10 Lassalle, F.: ¿Qué es una Constitución?, Ariel, Barcelona, 1984, pág. 84. 
la adecuación de la Norma Fundamental a las contingencias históricas, pero sin que ello suponga una vulneración de la misma, esto es, sin que tales adaptaciones perjudiquen o distorsionen lo que configura la esencia misma del ordenamiento ${ }^{11}$. En otras palabras, compatibilizar el cambio y permanencia del texto constitucional, de manera que, aun produciéndose las precisas modificaciones, pueda seguir identificándose en lo sustancial una determinada norma constitucional respecto a las demás.

Sin embargo, hay que señalar que, aunque la tesis de fondo como es la de conjugar el cambio - al que necesariamente se ven impelidos los textos constitucionales - y la permanencia -como respuesta a la estabilidad a la que normalmente tienden los Códigos Fundamentales - es aceptada ordinariamente por la doctrina, paradójicamente se muestra divergente en las aplicaciones prácticas de tal supuesto, al negar la existencia de determinados límites, que protegen la Constitución material, de la función revisora a fin de posibilitar su permanencia.

La notable rigidez detectada en el constitucionalismo moderno ${ }^{12}$ conduce a pensar en la cláusula de revisión como medio del que se sirven las Leyes Fundamentales para proyectar su permanencia a lo largo del tiempo, asegurando pues su continuidad, toda vez que se institucionaliza frecuentemente el modelo de rigidez para sus procesos de transformación ${ }^{13}$. Es sabido, que las Constituciones tienden a reflejar las creencias y los intereses dominantes, o bien los compromisos que liman los intereses en pugna ${ }^{14}$. El Constituyente sitúa ete imbricado conjunto de relaciones político-sociales en el seno del contexto constitucional, con el deseo de garantizarlas o proclamarlas, dotándole de una definitiva condición de rigidez. Afirmar tal evidencia no es nada

1 LuCas Verdú, P.: Curso de Derecho Político, vol. II, Tecnos, Madrid, 1977, pág. 533.

12 EsMEIN, A.: Droit Constitutionnel, vol. II, 7ème ed., Librairie Récueil Sirey, 1921, pág. 495.

13 BRYCE, J.: Constituciones flexibles y constituciones rigidas, Civitas, 2. ed., Instituto de Estudios Políticos, Madrid, 1962, págs. 94-95. Las constituciones flexibles no requeririan dispositivo alguno para su revisión, pudiéndoselas situar, al contrario de cómo acontece con las rígidas, en los mismisimos principios de las sociedades políticas organizadas, frecuentemente; salvo los supuestos en que su flexibilidad derive de la intencionada pretensión del Constituyente, de no dotar de ningún dispositivo en previsión a su reforma, aunque se trate de un texto escrito: como lo configura el supuesto de la Constitución Española de 1876.

14 WHEARE, K. C.: Las Constituciones modernas, op. cit. pág. 73. 
novedoso, sin embargo, es conveniente hacerlo, aunque sólo sea para centrar la atención en lo que sería el contrapunto a este justificado deseo de permanencia, que a través de la rigidez pretende la voluntad constituyente. Efectivamente, a pesar de la tendencia al modelo rígido que parece haber hecho fortuna si se contemplan los modernos textos constitucionales, se detecta, no obstante por parte de la doctrina, una tendencia que palia los efectos que se derivan del carácter rígido asumido por los Estatutos fundamentales. Nos referimos al sector que, por propugnar su tesis ignorando el reconocimiento de límites ${ }^{15}$, al poder de revisión, se sitúa como contrapunto en manifiesta oposición a la tendencia que los propios Códigos fundamentales asumen para asegurar su garantía de permanencia, proyectándose en el tiempo.

Pretender que las Constituciones en su rigidez lleven al extremo tal condición, de forma que se dificulten en la práctica sus procesos de evolución, por la dificultad que éstos entrañan, al punto de que la existencia de una cláusula de reforma, que acoplaría el ordenamiento a las nuevas exigencias político-sociales, se torne ineficaz, es una pretensión poco recomendable. En todo caso, configura uno de los medios más idóneos para que se produzca el resultado que se pretendía evitar: el fin de la Constitución. Pues obviamente, si el instrumento que ha de activarse para producir las modificaciones, lejos de habilitar un mecanismo simple, está dotado de unos dispositivos tales, cuya puesta en práctica hacen sumamente difícil su aplicación inmediata, los textos que observen estos sistemas de reforma, como consecuencia de su condición rígida, estarán más fácilmente abocados a que éstos se transformen de todas formas y lo hagan además de manera revolucionaria, sin seguir los procedimientos previstos constitucionalmente a tal efecto.

Pero si poco recomendable es la pretensión de la rigidez excesiva en las Constituciones al punto que dificultan extremadamente su acomodación a las nuevas necesidades, igualmente perjudicial para la salud a que todo orden constitucional debe aspirar, sería el resultado al que se derivaría de la inadmisibilidad de límites al poder de revisión que perfila una corriente doctrinal desde el periodo de la Segunda Guerra Mundial.

Tal pretensión produciría el efecto fulminante de poner en peligro asimismo el orden fundamental, porque igualmente arriesgado

15 Esta corriente doctrinal estaria representada por VANOSSI, BISCARETTI DI RUFFIA, entre otros. 
sería para el mantenimiento de la Constitución, concretada en el núcleo irreductible que la identifica y define, que la cláusula de revisión no estuviera sujeta a determinados límites que protegieran y defendieran el conjunto de elementos que sustentan la fórmula política ${ }^{16}$ en que se sustancia la Constitución material.

Consideramos que la función de revisión ha de proveer precisamente a la compatibilidad de la permanencia del Estatuto del poder, posibilitando paralelamente su transformación, así como a salvaguardar el núcleo identificativo de todo Código Fundamental.

De la eficacia en orden a la consecución de ambos objetivos, podrá deducirse si la función de revisión responde o no a la dirección asumida por el constitucionalismo moderno, cristalizando en el establecimiento de un régimen rígido de reforma, que asegure la permanencia del orden constitucional; pero esta permanencia no es realizable si, por otra parte, no se le conecta con los presupuestos identificadores, que sirven de parámetro para dilucidar si las modificaciones que afectan alTexto Fundamental asumen esta condición, en sentido estricto, que implicaría el acoplamiento de la Norma Superior a las nuevas exigencias que sobrevengan, o por el contrario se proyectan como una nueva manifestación constituyente, que obviamente excedería la función revisora, al afectar, precisamente, a aquellos presupuestos básicos que identifican el orden constitucional, y cuya modificación llevaría pareja la supresión de la misma.

Por lo que no podemos renunciar a una valoración bidimencional del significado que asume la función de reforma constitucional, referente, de una parte, a su manifestación como instrumento que habilita los propios procesos de transformación constitucionales, sin que ello obstaculice la permanencia del Estatuto: para seguir siendo debe admitir el ir dejando de ser. $Y$ de otro lado, atendiendo a la función de reforma como dispositivo idóneo para defender y garantizar el elemento identificativo de la Norma Suprema.

\section{JUSTIFICACIÓN DE LA ACTIVIDAD REFORMADORA COMO} CONSECUENCIA DE LA DIALÉCTICA: PERMANENCIA-CAMBIO

El instituto de revisión constitucional está orientado a suplir las deficiencias que toda Norma Fundamental puede experimentar, pero

16 Lucas Verdú, P.: Curso de Derecho Político, vol. II, op. cit., pág. 428. 
no debe instrumentalizarser sin embargo para un fin que tenga por objeto superar una posible crisis ${ }^{17}$ política, cuya solución a través del dispositivo de revisión implicara la eventual instauración de un nuevo orden constitucional completamente diferente, por producir la desconstitucionalización del sistema político de una comunidad estatal.

El constitucionalismo revolucionario ejemplarizó la tendencia a la permanencia de la Norma Fundamental, en su pretensión de asegurar a las futuras generaciones los hitos conseguidos por el liberalismo constitucional. Este deseo de permanencia se verifica al dotarse, en el constitucionalismo moderno, a las constituciones rígidas de específicos dispositivos para su reforma; el continuo mutar social impone inevitablemente la necesidad del cambio, precisamente para que pueda persistir la Ley Superior. Ello no hace sino materializar la idea consagrada ya en la Constitución Francesa de 1793 en cuyo artículo 28 establece: "Un pueblo tiene siempre el derecho a cambiar, revisar y reformar su Constitución. Una generación no puede someter a sus leyes a las generaciones futuras", generalizándose la conciencia de que bajo ningún concepto puede entenderse la Constitución como ley permanente y eterna ${ }^{18}$. La razón de esta afirmación obedece a tres motivos:

a) Por la necesidad de adaptación a la realidad sometida a continua evolución.

b) Por el envejecimiento de la norma fundamental a través del paso del tiempo.

c) Por las lagunas que se detectan en la Constitución a lo largo de su aplicación práctica.

Frente a procesos constitucionales como el supuesto británico ${ }^{19}$ donde al no existir un Código formal escrito, compatibiliza de manera ejemplar su permanencia adaptándose a la vez a las nuevas nece-

17 Esmein, A.: Éléments de Droit Constitutionnel, Tome 2, Librairie Récueil Sirey, 1921, pág. 501. "Lorsqu'un peuple a choisi mûrement une forme d'État déterminé... il est contraire d'inscrire dans sa Constitution la permission de démander à tout moment qu'on change cette formen. En el mismo sentido, ScHMIT, C.: La teoría de la Constitución, Alianza Edit., Madrid, 1982, pág. 120; BurDEAU, G.: Traité de Science Politique, tomo IV, Librairie Générale de Droit et Jurisprudence, París, 1969, pág. 252.

18 DE VEGA, P.: La reforma constitucional y la problemática del poder constituyente, Tecnos, Madrid, 1985, pág. 59.

19 Lucas Verdú, P.: Curso de Derecho Político, vol. II, op. cit., pág. 646. 
sidades, las constituciones escritas y rígidas manifiestan la tensión entre permanencia y cambio, de manera patente.

Dicha tensión evidencia la inevitable tendencia de todo ordenamiento a intentar conciliar ${ }^{20}$ el aspecto estático de sus normas originarias y las orientaciones impresas por las direcciones políticas que los órganos constitucionales formulan bajo el impulso dinámico de las fuerzas sociales. Pero más allá de la necesaria adaptación de estos factores - materializándose aquí muy especialmente dicha tensión-, parece primar la tendencia a la permanencia, cuando la adaptación del texto a las nuevas contingencias tuviera por objeto una transformación que afectara a su régimen político o fórmula política ${ }^{21}$. Lo que es comprensible porque si el constitucionalismo se caracteriza, muy especialmente, por la dinamicidad ${ }^{22}$ de su objeto, no puede por ello minusvalorarse - a pesar de la dinámica de los procesos de integración, continuamente en cambio - el carácter relativamente estático que la Norma Suprema asume, al traducirse en ella la decisión que el Constituyente definió.

¿Cómo superar pues la tensión existente derivada de la dialéctica permanencia-cambio constitucional?

Parece que el significado de permanencia implica, tácitamente, la idea de subsistencia del núcleo esencial ${ }^{23}$ de la Constitución, esto es, que las transformaciones que haya de experimentar el Texto constitucional sean asumidas por éste, en tanto en cuanto permita seguir reconociéndose en aquél las características propias que lo determinan, que son reconocidas por cierto sector de la doctrina como "superconstitución ${ }^{24}$.

En este sentido, cabría traducirse la dialéctica permanencia-cambio en verdadera estabilidad ${ }^{25}$ que se proyectaría sobre la base de que el orden constitucional absorbiera tales transformaciones pero activando, a su vez, las fuerzas que hacen posible el mantenimiento del

20 Bryce, J.: Constituciones flexibles y constituciones..., op. cit., pág. 138.

21 Lucas Verdú, P.: Curso de Derecho Politico, vol. II, op. cit., pág. 428.

22 HeLler, H.: Teoría del Estado, 6. ${ }^{a}$ reimpresión, Fondo de Cultura Económica, México, 1942, pág. 267.

23 De Vergottinl, G.: Derecho Constitucional Comparado, Espasa-Calpe, Madrid, 1983, pág. 166.

24 BARILE, P.: La costituzione come norme giurídica. Profilo sistematico, Barberá editore, Firenze, 1951, págs. 79 y ss.

25 Morlino, L.: Cómo cambian los regímenes políticos (trad. González Encinar), Centro de Estudios Constitucionales, Madrid, 1985, pág. 130. 
régimen político. Puesto que para que el régimen constitucional permanezca estable, esto es, que la tensión permanencia-cambio se trueque en estabilidad constitucional, es imprescindible ${ }^{26}$ que se produzcan transformaciones internas, pero suponiendo la continuidad de ciertas estructuras.

Esta estabilidad se consigue cuando la Norma Suprema aparece ante sus destinatarios actuales y los futuros como relativamente objetivada y despersonalizada, y sólo se logra su permanencia cuando puede mantenerse un equilibrio entre la normalidad y normatividad, durando, sí, la Norma más allá del momento presente, esto es, cuando consigue suscitar el sentimiento de adhesión constitucional ${ }^{27}$.

Mientras que si, por el contrario, la función revisora, desvirtuando su ejercicio, pretende asumir competencias que sólo al poder constituyente corresponden - por incidir en determinados aspectos fundamentales que identifican al ordenamiento-, todo posible equilibrio entre el grado de permanencia y cambio deseables, se habrá extinguido, pues lo que se produce es una supresión de la Norma Fundamental, con lo que toda pretensión de compatibilizar y armonizar la estabilidad y evolución del Instrumento Superior, a través del dispositivo de reforma, se torna ineficaz.

\section{BALANCE DE LA ACTIVIDAD DE REFORMA DE LA CONSTITUCIÓN ESPAÑOLA DE 1978}

Frente al balance que sobre la institución de la Reforma Constitución llevó a cabo, con acierto, Contreras ${ }^{28}$, en el que reflejaba una inaplicación, hasta ese momento, de las normas constitucionales que integraban el Titulo $X$ de la Constitución, cabe formular, tras los 25 años de existencia de la institución de reforma constitucional, un balance de la actividad revisora práctico, toda vez que, frente a lo que acontecía con el balance anteriormente referido, ya cabe afirmar que nuestro Texto Constitucional ha experimentado una reforma del mismo.

26 MoRlino, L.: Cómo cambian los regímenes..., op. cit., pág. 131.

27 LUCAS VERDÚ, P.: El sentimiento constitucional, págs. 66 y ss.

28 Contreras, M.: “Balance sobre el Título $X$ de la Constitución Española: De la Reforma Constitucional ", Revista de Derecho Político, n. ${ }^{\circ} 37$, UNED, Madrid, 1992. 
ElTratado de la Unión Europea acordado en Maastricht el 10 de diciembre de 1991 proyecto un movimiento revisionista en que adquirió especial relieve el Título $X$ de nuestra Constitución, toda vez que aquél incidía en las Constituciones de los Estados miembros de la Unión Europea, conduciendo a que los países más exquisitos en la depuración de sus textos normativos procedieran a reformar sus Constituciones, tal como afirmaba Muñoz Machado29.

Desde ese momento, se propaga a lo largo de Europa una tendencia generalizada dirigida a acoplar la Constitución de los paises miembros a las premisas acordadas en Maastricht.

\section{IV.A. Derecho comparado y Maastricht}

La adaptación a Maastricht se ha resuelto de manera distinta en el ámbito del Derecho comparado. Así, Alemania consideró que el desajuste sobrevenido entre la Ley Fundamental de Bonn y Maastricht obligaba a su reforma; Portugal, por su parte, descartó en principio reformar su Constitución, considerando que su texto normativo no presentaba contradicción con el Tratado europeo, en la medida que equipara los derechos y deberes del ciudadano portugués a los de los extranjeros residentes en Portugal.

En el supuesto de Francia, se ha procedido a aprobar la reforma de la Constitución Gaullista el 23 de junio de 1992, reunidos en Versalles la Asamblea Nacional y el Senado, constituidos en Congreso y consiguiendo una mayoría superior a las $3 / 5$ partes de los 895 miembros del Parlamento (592 votos a favor, contra 73), y ello a pesar de la cierta disensión o tensión detectada en el seno del Parlamento entre europeistas y eurófobos, al menos en lo que concierne alTratado de Maastricht, por considerarlo caduco tras el rechazo danés.

Para proceder a su reforma constitucional, Francia ha optado por el sistema de revisión ordinario del artículo 89 de la Constitución Francesa frente al excepcional previsto en su artículo 11.

En virtud de dicho procedimiento, el proyecto de reforma debía ser votado por las dos Cámaras en idénticos términos y ser aprobada posteriormente en referéndum para ser definitiva la reforma constitucional.

29 MuÑoz MACHADO, S.: La Unión Europea y las mutaciones del Estado, Alianza, 1993. 
Ahora bien, sucede que el mismo artículo 89, establece que el proyecto de reforma no será sometido a referéndum, cuando el Presidente de la República decida someterlo al Parlamento convocado en Congreso, y siempre que se obtenga una mayoría de $3 / 5$ partes de los votos emitidos. Tales requisitos prescritos en el art. 89 se cumplieron. Sin embargo, en este caso francés, se ha dado la circunstancia de que, a pesar de haber optado el Presidente por la vía del Congreso y, además, haber conseguido el porcentaje preciso de los 3/5 de las Cámaras - lo cual haría innecesaria la vía referendaria-, no obstante, se procedió a someter la reforma a referéndum popular para su adopción definitiva.

Esta consulta popular representaría el primer caso en que un proyecto de revisión constitucional que sigue el procedimiento previsto en el artículo 89 Constitución Francesa, es objeto de adopción definitiva por el pueblo, lo cual hizo que dicha revisión constitucional configurara uno de los ejemplos de reforma más inéditos de Francia, como ha afirmado el profesor Etienne Picard, y con la especial singularidad que tenía de innecesario tal referéndum.

Dinamarca, por su parte, zanjó la cuestión en un primer momento, sometiendo la consulta de adhesión alTratado de Maastricht a referéndum que aportaría un resultado negativo y que posteriormente reconduciría en un segundo referéndum.

\section{IV.B. Balance de la Reforma Constitucional en España}

\section{IV.B.1. Concepción de la Reforma Constitucional por el Constituyente}

Como vimos en los epígrafes anteriores (II y III), nuestro Constituyente dotó de un definido carácter de rigidez a nuestro Texto fundamental para cada uno de los dos procedimientos admitidos para activar el dispositivo de la reforma: tanto el previsto en el art. 167 como ordinario, así como el contemplado en el art. 168 como agravado. Por ello, nos parece especialmente significativo el carácter rígido que contempla el Título $X$ como reflejo de la concepción de nuestro Constituyente, en la pretensión de lograr una estabilidad integral de la Constitución, en la línea que señaló Jiménez Campo ${ }^{30}$, al afirmar: «EI

30 JIMÉnEZ CAMPO, J.: “EITítulo X de la Constitución», en Revista del Departamento de Derecho Político, n. ${ }^{\circ} 7$, otoño, UNED, 1980. 
alcance de la normativa constitucional sólo se logra cuando el texto garantiza - mediante los procedimientos de revisión- la estabilidad elemental, como una respuesta adecuada al cambion.

Así, el procedimiento por el que optó nuestro Constituyente pretendía equidistar entre la flexibilidad absoluta de la que hicieron gala algunas de nuestras Constituciones históricas, así como de aquellas otras que adoptaron un supercomplicado procedimiento para su revisión, como la doceañista o la de 1931, acaso pretendiendo lograr un punto de equilibrio ecléctico entre la irreformabilidad absoluta y la flexibilidad a ultranza, proyectando, pues, la opción reformadora que reflejó el constituyente en nuestra Norma Fundamental la intención de garantizar la subsistencia del orden constitucional, pero compatibilizándola a su vez con la necesaria evolución y acoplamiento del texto a las nuevas exigencias político-sociales.

\section{IV.B.2. Supuestos de actividad reformadora en la Constitución Española de 1978}

El devenir del tiempo, así como la aplicación y práctica institucional, han permitido detectar determinados aspectos jurídico-constitucionales que, o bien han sido superados por el acontecer políticosocial, o bien reflejan un inadecuado funcionamiento. Esta realidad ha proyectado en la doctrina una cierta posición de filias y fobias en lo que concierne a reformar la Constitución.

Así, un sector de la doctrina representado por Jiménez de Parga, no abrigaba ningún perjuicio en reformar la Constitución, entendiendo que cuando nuestro Texto Constitucional de 1978 se redactó todavía existian unas fronteras que nos separaban mucho del resto de los paises europeos.

ElTratado de Maastricht planteó una posible discordancia entre la adopción del mismo y nuestra Norma Fundamental. El Gobierno procedió a requerir al Tribunal Constitucional, atendiendo la prescripción constitucional del artículo 95.2, que le legitima a requerir a aquel Tribunal para que se pronuncie sobre si existe o no contradicción entre la celebración de un Tratado y la Constitución, a fin de que se manifestara al respecto sobre la eventual contradicción entre el artículo 8.B delTratado de la Unión Europea: «Todo ciudadano de la Unión que resida en un Estado miembro del que no sea nacional, tendrá derecho a ser elector y elegible en las elecciones municipales del Estado miembro en el que resida, en las mismas condiciones que los nacionales de 
dicho Estadon; $y$, por su parte, el art. 13.2 CE, que omitía la posibilidad de sufragio pasivo para los extranjeros.

El Tribunal Constitucional realizó un control preventivo (art. 78 L.O.T.C.) que, como es sabido, no equivale a un recurso, por ello la Constitución no habla - como ha señaladoTorres del Moral-ni de sentencia, ni de recurso, sino de requerimiento.

La declaración al respecto del Tribunal Constitucional tendria carácter vinculante, conforme define el art. 78.2 L.O.T.C., así como el propio Tribunal cuando afirmaba: "Lo que de nosotros puede solicitarse es una declaración, no un dictamen, una declaración, no una mera opinión fundada en derecho, decisión, además, vinculante».

Desde la perspectiva del reconocimiento por parte del Tribunal Constitucional, de una contradicción entre la Unión Europea y nuestra Constitución, se abrian varias vías:

1. Volver a renegociar el texto del Tratado.

2. Incluirse reservas en el texto del mismo.

3. Reformar la Constitución.

4. Renunciar al Tratado.

Cualquier vía que no fuera la de reforma de nuestro texto, supondría una regresión en la integración europea. La decisión de reformarlo fue adoptada por el Alto Tribunal por unanimidad.

Habiendo prosperado la Declaración del Tribunal Constitucional en la línea de reformar la Constitución, por activación del art. 95.1. CE, tal revisión se efectuaría por la vía del artículo $167 \mathrm{CE}$, esto es, por el procedimiento ordinario, que exige la mayoría de $3 / 5$ de cada Cámara (210 votos en el Congreso y 153 en el Senado); o, en su caso, por mayoría de 2/3 del Congreso y siempre que el Senado hubiere obtenido la mayoría absoluta, y no siendo necesario someter la reforma a referéndum, si no lo solicita la décima parte de los miembros de cualquiera de las Cámaras (35 Diputados o 25 Senadores). Circunstancia ésta, por lo demás, no que se dio.

En consecuencia, la Constitución de 1978, en fecha 20 de agosto, BOCG, $n .^{\circ} 147-5$, y publicada en el BOE en fecha de 28 de agosto de 1992, experimentó su primera - y única - reforma de manera un tanto precipitada, frente a la postura contraria a introducir reformas en el texto fundamental, adoptada por un sector de la sociedad, e incluso por parte del Gobierno que no se manifestaba especialmente proclive a introducir reformas. 
Recurrir a cualquiera de los argumentos esgrimidos a la sazón por el Gobierno y por el Consejo de Estado para soslayar la reforma de la Constitución - tal como la vía del art. $93 \mathrm{CE}$, que permitiría la posibilidad de atribuir a una institución internacional el ejercicio de determinadas competencias derivadas de la Constitución, a través de una Ley Orgánica - hubiera constituido a mi parecer un más que lamentable subterfugio jurídico, con la única finalidad de evitar un mecanismo jurídico constitucional, previsto específicamente para tal fin, $y$ que no hay que temer ponerlo en práctica, pues como, con acierto, señala Pérez-Royo: «Es saludable para la propia vida de la Constitución".

En definitiva, se trata de desmitificar la aplicación práctica de reforma de la Constitución cuando tal actividad se refiera efectivamente a una función transformadora "constituida", ya que para eso está.

Francia ha reformado 5 veces su Constitución desde 1958 y no pasa nada, ni ha sido tanto su desgaste. Por el contrario, asegura mejor su subsistencia al adaptarse a las nuevas necesidades del devenir político social.

\section{PERSPECTIVAS DE POSIBLES READAPTACIONES DELTEXTO CONSTITUCIONALTRAS 25 AÑOS DE EXISTENCIA: LA REFORMA CONSTITUCIONAL ANTE LAS DEMANDAS SOCIALES DE NUEVA GENERACIÓN}

Nuestra sociedad actual, presidida por la tendencia generalizada del bienestar material, ha llegado a un punto de inflexión en el que concurren intereses humanos que corresponden a dos ámbitos de delicada vertebración:

- De una parte, el avance científico en la esfera de la biomedicina y particularmente en torno a la reproducción artificial asistida y la clonación.

- Y, de otra parte, la proyección ética predicable del hombre, asépticamente considerada, al margen de connotaciones religiosas, y que recae en el hombre, en su ethos, en sus costumbres.

Desde esta consideración cabe afirmar que el debate social implicado no puede plantearse desde una perspectiva unidimensional que prime una sola de las esferas implicadas: sería poco deseable formu- 
lar el tema de la reproducción asistida y clonación desde la exclusiva óptica del imparable avance científico suministrado por la biomedicina,; la huída hacia delante del "todo es válido" en la medida que colme las pretensiones de una sociedad cada vez más evolutiva y dinámica en sus valores trascendentes, no es de recibo. De igual modo sería improcedente e inaceptable plantearlo poniendo barreras al imparable progreso cientifico.

La imbricación de estos dos ámbitos profundamente entreverados obliga a una reflexión en torno a la conveniencia de adaptar la Constitución a las nuevas contingencias que plantea nuestra realidad social, en materia del progreso de las Ciencias Biomédicas, tanto sobre aspectos derivados de las técnicas de reproducción asistida como sobre técnicas de clonación, desde el enfoque con el que W. T. Reich proyecta la bioética: «el estudio sistemático de la conducta humana en el área de las ciencias de la vida examinadas a la luz de los valores y principios morales". Atendiendo a esta afirmación nos planteamos si cabe llegar a un punto de encuentro entre el progreso científico -que considero debe ser seguir su camino - y la bioética, a través del reconocimiento de unos límites éticos no a la investigación científica, sino, en todo caso, a su aplicación práctica - que posibilite la concurrenciacomo afirmaba E. Sgreccia entre: «la filosofía moral de la investigación y la práctica biomédican, de tal manera que confluyan progreso científico y ética, sin menoscabo alguno de aquél, pero sin vulneración de ésta.

El avance tecnológico en las ciencias de la biomedicina es un hecho probado. Falta resolver el problema ético y jurídico-constitucional para que aquel avance científico no arrolle el principio de dignidad humana inherente al hombre que contempla nuestra Constitución. El progreso de la ciencia biomédica ha supuesto la expansión de nuevos derechos humanos: derecho a procrear o no procrear; derecho a un patrimonio genético no manipulado; derecho a la identidad; derecho a la unicidad; derecho a la diferenciación; derecho a la familia con padre y madre; derecho a la privacidad o a no conocer predisposiciones patológicas; etc., aspectos que configuran una nueva generación de derechos no contemplados en la Constitución. Por otra parte, la manipulación de preembriones y de embriones que contempla el art. 11.3 de la Ley de Técnicas de Reproducción Asistida (LTRA) roza en varios supuestos con el principio de la dignidad humana que contempla el art. 10 de nuestra Constitución: la cautividad durante 5 años de material genético en estado de crioconservación obtenido de embriones sobrantes atraviesa por una doble denigración: impide o dificulta el desarrollo de la persona (art. 9.2 CE); atenta contra la dignidad huma- 
na (art. $10 \mathrm{CE}$ ) y por último contraviene la finalidad que la propia LTRA define en su artículo 1.2: la procreación, toda vez que impide a los preembriones humanos desarrollarse. Pero además, ¿qué se hace con ese material genético tras 5 años? Al margen del traspaso de titularidad lo que ya en si es aberrante - del propietario, que pasaría a ser el banco de crioconservación (art. 11.4 LTRA), ¿qué viabilidad se vislumbra para los preembriones sobrantes y en expectativas de convertirse tras 9 meses en ser humano?

De otra parte, ¿cómo solucionar el problema de orden penal que se suscita al practicarse un aborto, tras una eventual hiperestimulación hormonal y posterior implantación en útero materno, cuando 3 ó 4 ó 5 embriones son viables y se opta por dar cauce sólo a 1? $\mathrm{Ni}$ el aborto eugenésico, ni el ético ni el terapéutico dan cobertura a esta figura nueva de aborto que no contempla el Código Penal como causa de despenalización parcial del aborto. Las técnicas de clonación humana, sin perjuicio de sus virtudes terapéuticas, deben prevenir o garantizar aquellos derechos de unicidad, identidad, no selección de la raza, etc. Creemos que la postura de un gobierno de trasladar a los padres el centro de decisión sobre la autorización a la manipulación o no manipulación genética, no le exime de la responsabilidad que por obvias razones civiles no puede desatender.

Ante estas circunstancias, ¿puede permanecer estática e insensible nuestra Constitución, o, por el contrario, debe dar cobertura a los cambios que el proceso tecnológico comporta? Nuestro constituyente no pudo en 1978 prever las demandas sociales actuales, pero plasmó en la Constitución el mecanismo adecuado para acompasar la vida de ésta a las nuevas exigencias del devenir social, sin que para ello hubiera que forzar la interpretación de la Norma más allá de los límites que el buen hacer jurídico-constitucional aconseje.

No es el momento de valorar el quantum sustancial del alcance de la reforma constitucional que pudiera acometerse, pero sí conviene recordar que la técnica de reforma que contempla nuestra Constitución para adaptarse a las nuevas necesidades de nuestra sociedad permite desde una simple modificación parcial a una revisión total que implicaría la supresión de la Constitución. Existen, pues, dispositivos constitucionales para metabolizar los cambios evitando que nuestra Constitución sea meramente nominal, el reto es la voluntad o no de acometerlos. 